Indexaciones: Repositorio de Revistas UCR, DIALNET, Latindex, REDALYC Directorio y recolector de recursos digitales del Ministerio de Cultura de España, Directory of Open Access Journals. Diálogos Revista Electrónica de Historia ISSN 1409-469X. Número especial 2008. Dirección web: http://historia.fcs.ucr.ac.cr/dialogos.htm

\title{
Un estudio comparado del establecimiento de logias masónicas en Costa Rica y Guatemala (1865-1903)
}

\author{
Ricardo Martínez Esquivel
}

Estudiante de maestría académica en Historia de la Universidad de Costa Rica. Correo electrónico: shoremricardo@yahoo.es 


\section{Introducción}

E1 28 de junio de 1865 es organizada de manera oficial la primera logia centroamericana con el nombre de "Caridad” en San José, Costa Rica. Durante el resto del siglo XIX se fundarían constantemente nuevas logias en Centroamérica, las cuales iniciarían a individuos de distintas nacionalidades en esta asociación. Por tanto, el objetivo de esta investigación está en realizar un estudio comparado entre Costa Rica y Guatemala del desarrollo cronológico-espacial de la masonería.

El presente trabajo está delimitado temporalmente de 1865 a 1903. La primera fecha corresponde al año de la organización de la masonería y la segunda al año de la fundación de la "Gran Logia de Guatemala". Este trabajo abarcará las ciudades de Guatemala, Sacatepéquez, Quetzaltenango, Retalhuleu, Totonicapán, San Marcos y Alta Verapaz, en Guatemala; y San José, Puntarenas, Cartago, Alajuela, Limón y Liberia, en Costa Rica; todos lugares donde se organizaron logias masónicas. La problemática que buscamos responder: ¿Qué factores condicionaron el proceso de expansión de la masonería en Costa Rica y Guatemala entre los años de 1865 y 1903 ?

\section{Organización de la masonería en Centroamérica}

El momento específico en que llega la masonería a Latinoamérica ${ }^{1}$ es uno de las grandes interrogantes en la historia de esta "sociedad de ideas".² Pero lo que sí está claro, es que su desarrollo ha sido un proceso complejo debido a la impugnación que ha ejercido parte del clero de la Iglesia católica y algunas élites políticas no liberales. La visión idealista-simbólica de

1 Lo que si sabemos es que el auge de actividades masónicas en la región va a desarrollarse entre 1880 y 1930, durante la hegemonía de los estados liberales, véase Fortunato Malimacci, "Catolicismo y liberalismo: las etapas del enfrentamiento por la definición de la modernidad religiosa en América Latina”, Jean Pierre Bastian, La modernidad religiosa: Europa latina y América latina en perspectiva comparada. México, Fondo de Cultura Económica, 2004, 23-31

2 Este concepto es de Augustin Cochin ("sociétes de pensée"), y se refiere a las formas modernas de sociabilidad que surgen en el marco de libertades de especulación intelectual que propició la ilustración francesa, las cuales ofrecen nuevos modelos asociativos en torno a una estructura corporativa y jerárquica, y compuesta por actores sociales colectivos. La categoría de análisis "sociétés de pensée" ha sido modificada genéricamente por Bastian como "sociedades de ideas", ello a partir de sus investigaciones sobre México. Véase Bastian, Los disidentes. Sociedades protestantes y revolución en México 1872-1911, México, el Colegio de México, 1989, 32 
la masonería, sus reuniones de carácter secreto y su participación en diferentes procesos de laicización y secularización, ${ }^{3}$ han provocado que la institución eclesial principalmente, vea a esta agrupación como un ente amenazante y conspirador al orden social.

Sin embargo, ha sido la promoción del racionalismo y la libertad absoluta de la consciencia, lo que ha llevado a parte del clero católico a preocuparse, ya que en el discurso eclesial, las personas en una condición como ésta de "libre albedrío" corren el riesgo de extraviarse y perder su alma. Por ende la Iglesia católica reaccionó en su deber de orientar y salvar al ser humano para tenerlo siempre junto a Dios. ${ }^{4}$ Entonces los distintos papas dictan documentos condenatorios a la sociabilidad masónica, ${ }^{5}$ esto en un contexto de lucha contra el liberalismo por parte del Vaticano.

Luego de las independencias latinoamericanas, buscando mantener su protagonismo en los distintos países, la Iglesia católica empieza a firmar concordatos con los nuevos estados. ${ }^{6}$ El 28 de febrero de 1850 el Vaticano reconoce a la ahora República de Costa Rica como un estado independiente, ello por medio de la bula Christianae religionis auctor; siendo esta la causa por lo cual se nombra al primer obispo del país, Anselmo Llorente y Lafuente. Con este reconocimiento papal, serían iniciadas las relaciones de corte político, entre el país y la Iglesia. Para el 7 de octubre de 1852, Costa Rica y Guatemala firman su primer concordato (de paso mismo texto), donde incluso en su primer artículo se asevera:

"La Religión Católica Apostólica Romana es la Religión del Estado en la República de (Costa Rica o Guatemala), y se conservará siempre con todos los derechos, y prerrogativas de que debe

3 Diferenciamos secularización de laicización siguiendo a Baubérot, donde en el primero predomina lo cultural y en el segundo lo institucional, véase Jean Baubérot, La laicité, quel heritage?, Ginebra: Labor et FIDES, 1990

4 Recordemos que la Iglesia católica considera que posee el derecho divino de meterse y limitar libertades como el uso de la razón, de saber que es malo o bueno, si esto puede extraviar o incluso condenar al individuo 5 Ricardo Martínez Esquivel, "El discurso de la Iglesia católica sobre el fenómeno de la masonería en Costa Rica (1865-1899)”, Jornadas de Investigación Histórica, CIHAC, Universidad de Costa Rica, San José, Costa Rica, 2008

6 Un concordato es un documento ratificado por la Santa Sede y un estado, para regular las relaciones entre éste y la iglesia local radicada en su territorio. La Santa Sede interviene en virtud de soberanía espiritual y el estado nacional admite un estatuto particular a la religión católica. En los concordatos del siglo XIX, el estado reconoce la importancia del catolicismo al extremo de declararse confesional. Miguel Picado, "Los concordatos celebrados entre los países de Centro América y la Santa Sede durante el siglo XIX”, Revista de Historia (Heredia) 28 (1993): 208-211 
gozar según la ley de Dios y las disposiciones de los sagrados Canones”.?

Lo anterior implicaba para ambos países aliarse a las políticas de la Iglesia católica, entre las que estaban la lucha contra la masonería. Para dicho año en Centroamérica no existía masonería organizada, pero sería trece años después cuando se organizaría la primera logia masónica en Costa Rica bajos los auspicios del Gran Oriente y Supremo Consejo Neo-Granadino. ${ }^{8}$

\section{PERIODOS DE LA MASONERÍA DURANTE EL SIGLO XIX}

El desarrollo de la masonería en Centroamérica durante el siglo XIX se ha sido dividido de diferentes maneras. Rafael Obregón Loría considera los periodos 1865-1871, 1871-1887 y 1887-1899; 9 mientras que Miguel Guzmán-Stein, explícitamente para el caso costarricense, $1865-1874,1882-1887$ y $1887-1899 .{ }^{10}$

Obregón explica sus periodos en relación al gran auspiciador con autoridad en Costa Rica o bien en la sede de éste. De 1865 a 1871, el gran oriente auspiciador fue el Gran Oriente y Supremo Consejo Neo-Granadino con sede en Cartagena, Colombia; esto con excepción de la logia Unión Fraternal en San José, la cual fue auspiciada por la Gran Logia de Colón con sede en La Habana, Cuba. Luego, a partir de 1871 y hasta 1899, el Gran Oriente y Supremo Consejo Centro Americano fue el auspiciador oficial de la masonería en la región; éste de 1871 a 1887 tuvo su sede en San José, pero a partir de 1888 se trasladó a la ciudad de Guatemala. ${ }^{11}$ Debemos tener en cuenta que con cada cambio de auspiciador, las logias cambian de número.

Por otro lado, Guzmán justifica su primer periodo (1865-1874) debido a un crecimiento

$7 \quad$ Picado, 214

8 Archivos de la Gran Logia de Costa Rica (AGLCR), Gran Oriente Neogranadino, Rejistro Oficial Masónico (Cartagena) 34 ( $1^{\circ}$ de agosto de 1865): 313-317

9 Rafael Obregón Loría y George Bowden, La Masonería en Costa Rica (Obregón, Masonería), Tomos I, San José: Trejos Hermanos, 1938, 4

10 Miguel Guzmán-Stein, "Base de datos para la historia de la masonería en Costa Rica en el siglo XIX", José Antonio Ferrer Benimeli, La Masonería en Madrid y en España del siglo XVIII al XXI, Zaragoza: CEHME, Tomo II, 2004, 1388-1389

11 Arthur George Malin Gillot, "El traslado del Gran Oriente a Guatemala y el cierre conjunto de todas las logias en Costa Rica”, Documentos Históricos referentes a la Masonería en Costa Rica, Gran Logia de Costa Rica, San José: Imprenta y Encuadernación Alsina, 1926; y Obregón, Porqué se trasladó a Guatemala el Supremo Consejo Centroamericano, San José: Imprenta Tormo, 1952 
constante, el cual como veremos más adelante en el Gráfico 1 no es tan cierto. El segundo lo explica con la vida de la logia Unión Fraternal desde 1882 hasta 1887 con el traslado del Gran Oriente y Supremo Consejo Centro Americano a la ciudad de Guatemala, pero la logia Unión Fraternal fue fundada el 9 de marzo de 1883. ${ }^{12}$ Por último, su tercer periodo inicia en 1887 con la fundación de la logia Regeneración, pero esta logia se fundó el 11 de noviembre de $1888 .{ }^{13}$

En nuestro caso, hemos periodizado la masonería del siglo XIX en cuatro periodos de organización de logias identificados, los cuales son 1865-1870, 1873-1875, 1880-1883 y 18861903. El estudiar el desarrollo de la actividad masónica en Centroamérica a partir de dicha periodización, nos ha permitido una mayor identificación de indicadores del proceso en estudio, en consiguiente un análisis más minucioso del desarrollo de esta sociedad de ideas en Costa Rica y Guatemala.

Con la fundación Caridad, iniciaría en la región un proceso de actividad masónica bastante complejo. Lorenzo Montúfar, guatemalteco radicado en Costa Rica para este momento y miembro de dicha logia, describe el impacto que ésta produjo de la siguiente manera:

“...hubo en Costa Rica una cuestión interesante que arrojó mucha luz sobre asuntos religiosos, políticos y sociales. Algunos individuos expulsados del país, con motivo de la caída de Juan Rafael Mora, se dirigieron a diversas naciones de América, donde se afiliaron en logias masónicas de todos los ritos, especialmente del antiguo escocés aceptado, y al volver a Costa Rica abrieron logias en aquel país. El primer obispo de Costa Rica, Anselmo Llorente y Lafuente, se indignó contra aquella nueva creación y lanzó una pastoral. El obispo me eligió como blanco de esa pastoral porque tenía yo el carácter de orador de la Logia Caridad, posición que me hacía notable. Yo contesté aquella pastoral y mantuve la polémica con el obispo, para lo cual me sirvió mucho mi periódico titulado El Quincenal Josefino. No sé si el éxito sería feliz, pero lo cierto es que desde entonces quedó fundada la masonería en Costa Rica”. ${ }^{14}$

Es entonces en el descrito cuadro de tensión, donde inició la difusión y el establecimiento de logias masónicas en la región centroamericana, en un proceso que consideramos de consolidación en Costa Rica y Guatemala, que finalizaría el 7 de diciembre de 1899 con la organización de

12 Museo Gran Logia de Costa Rica (MGLCR), "Registro de firmas Respetable Logia Unión N 19, 1883- 
la Gran Logia de Costa Rica y el 8 de agosto de 1903 con la organización de la Gran Logia de Guatemala, respectivamente.

\section{Cuadro 1}

Periodos de la Masonería en Guatemala y Costa Rica (1865-1903)

\begin{tabular}{|c|c|c|c|c|}
\hline \multirow[b]{2}{*}{ Periodos } & \multicolumn{3}{|c|}{ Logias organizadas } & \multirow[b]{2}{*}{$\begin{array}{l}\text { Total } \\
\#(\%)\end{array}$} \\
\hline & $\begin{array}{c}\text { Guatemala } \\
\quad \#(\%)\end{array}$ & $\begin{array}{c}\text { Costa Rica } \\
\#(\%)\end{array}$ & $\begin{array}{c}\text { Resto de Centroamérica* } \\
\text { \# (\%) }\end{array}$ & \\
\hline $1865-1870$ & $1(12,5 \%)$ & $5(62,5 \%)$ & $2(25 \%)$ & $8(100 \%)$ \\
\hline $1873-1875$ & $1(14,5 \%)$ & $5(71 \%)$ & $1(14,5 \%)$ & $7(100 \%)$ \\
\hline $1880-1883$ & $1(14,5 \%)$ & $1(14,5 \%)$ & $5(71 \%)$ & $7(100 \%)$ \\
\hline 1886-1903 & $11(35,5 \%)$ & $7(22,5 \%)$ & $13(42 \%)$ & $31(100 \%)$ \\
\hline Total & $14(26 \%)$ & $18(34 \%)$ & $21(40 \%)$ & $53(100 \%)$ \\
\hline
\end{tabular}

*Incluye los datos de El Salvador, Honduras, Nicaragua y Panamá.

Fuente: Biblioteca de la Gran Logia de la Isla de Cuba, Constitución del Supremo Consejo de Colón y de sus Cuerpos Subordinados. Rito Escocés Antiguo y Aceptado, La Habana: Imprenta El Siglo XX, 1922, 22; Francisco Medal, La historia de la Francmasonería en Nicaragua, Managua: Gran Logia de Nicaragua, 1927; José Oller, Historia del Supremo Consejo Nacional de Panamá, Panamá: Ediciones de la Imprenta Hernández, 1934; Federico Góngora Herrera, Documentos de la Masonería Centroamericana (Antigua y Aceptada). Desde el año 1824-1933, Serenísima Gran Logia de Costa Rica, San José: Imprenta Española, 1937; Góngora, Mis últimos documentos de la Masonería Centroamericana Antigua y Aceptada. Años 1809-1939, Serenísima Gran Logia de Costa Rica, San José, 1940; Rafael Obregón Loría, y George Bowden, La Masonería en Costa Rica (III Tomos), San José: Trejos Hermanos, 1938-1940; Obregón, José Quirce Filguera, fundador de la masonería en la República de Guatemala, San José: Imprenta Tormo, 1951; Obregón, Porqué se trasladó a Guatemala el Supremo Consejo Centroamericano, San José, Costa Rica: Imprenta Tormo, 1952; Francisco J. Ponte Domínguez, Historia de la Masonería Salvadoreña, Sonsonate: Imprenta Excélsior, 1962; Gran Logia de Guatemala, “Antecedentes de la Fundación de la Gran Logia de Guatemala” http://www.granlogiaguatemala.com/historia.htm (Fecha de acceso: 25 de marzo 2008)

El Cuadro 1 muestra los periodos de la masonería en Centroamérica hasta 1903, los cuales se caracterizaron por ser intervalos de años donde se organizaron nuevas logias. Observamos que en los dos primeros periodos, Costa Rica posee la mayor actividad masónica, poseyendo el 62,5\% y el 71\% de las logias organizadas en la región para dichos años. Para los años 1880-1883, 
en Guatemala y Costa Rica, tan sólo es organizada una logia en cada país, cuando en el resto del istmo fueron organizadas cinco. En el último periodo, Guatemala toma la delantera en lo que respecta a la organización de logias, son fundadas once que equivalen al 35,5\% del periodo, las cuales impulsarían el establecimiento de la Gran Logia de Guatemala. Costa Rica no se queda atrás y antes de la organización de su gran logia en 1899, son organizadas siete nuevas logias.

Mapa 1

Desarrollo cronológico-espacial de las logias masónicas en Guatemala y Costa Rica (1865-1903)

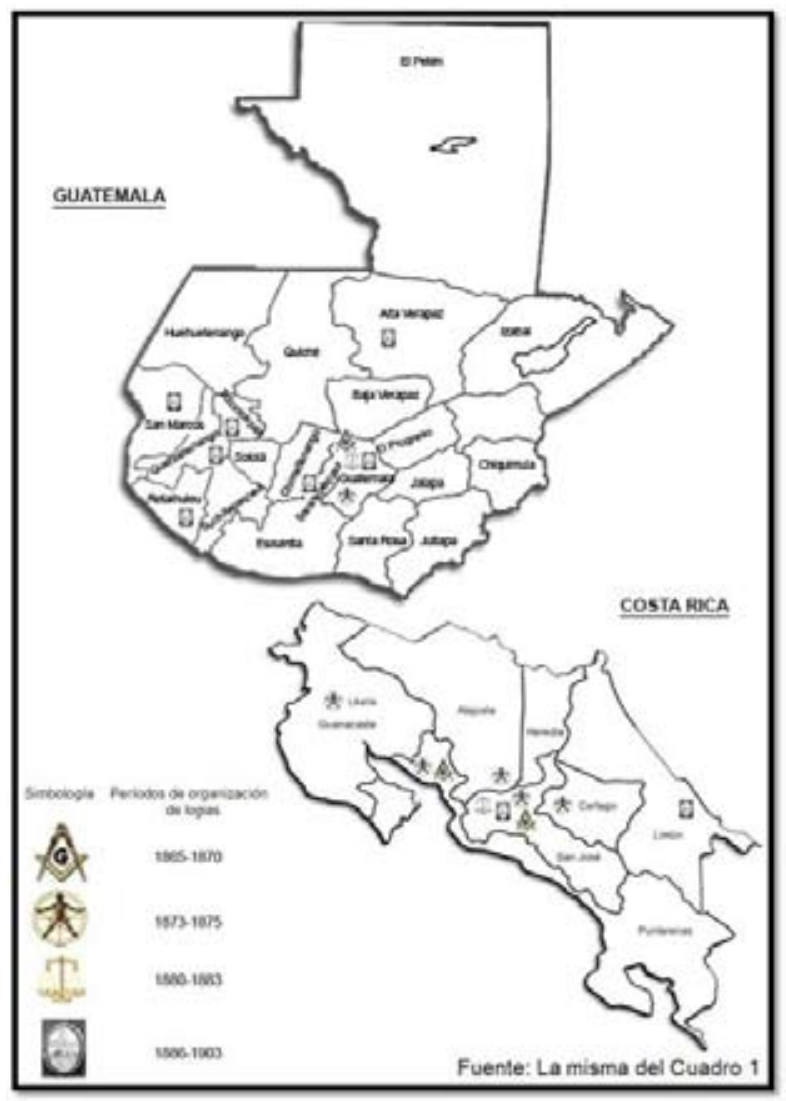

El Mapa 1 muestra la difusión cronológica-espacial de las 32 logias organizadas entre 1865 y 1903 en los países en estudio. A partir de éste vemos cómo entre 1873 y 1875 la masonería en Costa Rica experimentó el momento de mayor expansión en el país; se organizaron logias en 
las ciudades de San José, Alajuela, Cartago, Puntarenas y Liberia. Por otra parte, es en el último periodo cuando Guatemala experimenta el momento con mayor difusión de la sociabilidad masónica; son organizadas logias en Guatemala, Sacatepéquez, Quetzaltenango, Retalhuleu, Totonicapán, San Marcos y Alta Verapaz. Además podemos observar que durante los cuatros periodos hubo logias funcionando en las ciudades de San José y Guatemala, lo cual tiene sentido al ser éstas las capitales de determinados países.

\section{Cuadro 2}

Número de logias por ciudad en Costa Rica (1865-1899)

\begin{tabular}{|c|c|c|c|c|c|c|c|}
\hline Periodos & San José & Alajuela & Cartago & Puntarenas & Limón & Liberia & Total \\
\hline $1865-1870$ & 4 & & & 1 & & & 5 \\
\hline $1873-1875$ & 1 & 1 & 1 & 1 & & 1 & 5 \\
\hline $1880-1883$ & 1 & & & & & & 1 \\
\hline 1886-1903 & 3 & & & & 4 & & 7 \\
\hline Total & 9 & 1 & 1 & 2 & 4 & 1 & 18 \\
\hline
\end{tabular}

Por otra parte, en el Cuadro 2 se muestra la cantidad de logias organizadas en Costa Rica por periodo y ciudad. Observamos que en los años iníciales de actividad masónica en Costa Rica (1865-1870), la organización de logias se concentró en la ciudad capital con cuatro logias y una en la ciudad de Puntarenas. En el siguiente periodo, la masonería experimenta un importante proceso de expansión espacial, son organizadas logias en cinco ciudades diferentes, Alajuela, Cartago y Liberia se suman a las dos ciudades anteriores. Por último, vemos que en el periodo de 1888 a 1899, las siete logias organizadas fueron en tan sólo dos ciudades, San José y Limón. 


\section{Cuadro 3}

Número de logias por ciudad en Guatemala (1865-1903)

\begin{tabular}{|c|c|c|c|c|c|c|c|c|}
\hline Periodos & Guatemala & Sacatepéquez & Quetzaltenango & Retalhuleu & $\begin{array}{c}\text { San } \\
\text { Marcos }\end{array}$ & Totonicapán & $\begin{array}{c}\text { Alta } \\
\text { Verapaz }\end{array}$ & Total \\
\hline $\begin{array}{c}1865- \\
1870\end{array}$ & 1 & - & - & - & - & - & - & 1 \\
\hline $\begin{array}{c}1873- \\
1875\end{array}$ & 1 & - & - & - & - & - & - & 1 \\
\hline $\begin{array}{c}1880- \\
1883\end{array}$ & 1 & - & - & - & - & - & - & 1 \\
\hline $\begin{array}{c}1886- \\
1903\end{array}$ & 5 & 1 & 1 & 1 & 1 & 1 & 1 & 11 \\
\hline \\
Total
\end{tabular}

En el Cuadro 3 observamos la cantidad de logias por departamentos guatemaltecos. Vemos que en cada periodo de organización de logias, la ciudad de Guatemala poseyó una. La primera logia fue organizada en 1870 por F. E. Asturias, F. C. Castañeda y Juan F. Rodríguez y auspiciada por la Gran Logia de Colón. Esta logia se encontraba en el Callejón Manchen 4 de la ciudad de Guatemala. ${ }^{15}$ El dato anterior es importante porque hasta la fecha la historiografía a partir del trabajo de Obregón, ${ }^{16}$ había señalado que la primera sociedad de ideas masónica guatemalteca fue organizada en 1873 por José Quirce. Por otro lado, observamos que en los años de 1886 a 1903 fueron organizadas once logias en siete ciudades diferentes, importante expansión de actividades masónicas que impulsaría la organización de la Gran Logia de Guatemala y la consolidación de esta sociabilidad en este país.

El Gráfico 1 presenta el crecimiento cronológico de logias masónicas por periodo de organización de éstas en Costa Rica y Guatemala. Entre 1865 y 1903 podemos sumar el establecimiento de 32 sociedades de ideas masónicas entre los dos países. Por otra parte, podemos observar en el Gráfico 1 que la actividad masónica en Costa Rica no fue constante. A 15 Biblioteca de la Gran Logia de la Isla de Cuba, Constitución del Supremo Consejo de Colón y de sus Cuerpos Subordinados. Rito Escocés Antiguo y Aceptado, La Habana: Imprenta El Siglo XX, 1922, 22

16 Obregón, José Quirce Filguera, fundador de la masonería en la República de Guatemala, San José: Imprenta Tormo, 1951 
partir de éste vemos que en el periodo de los años 1880 y 1883, en Costa Rica es organizada tan sólo una logia, cuando en los periodos anteriores fueron organizadas cinco en cada uno; además recordemos que para estos años las logias anteriores ya no funcionaban.

\section{Gráfico 1}

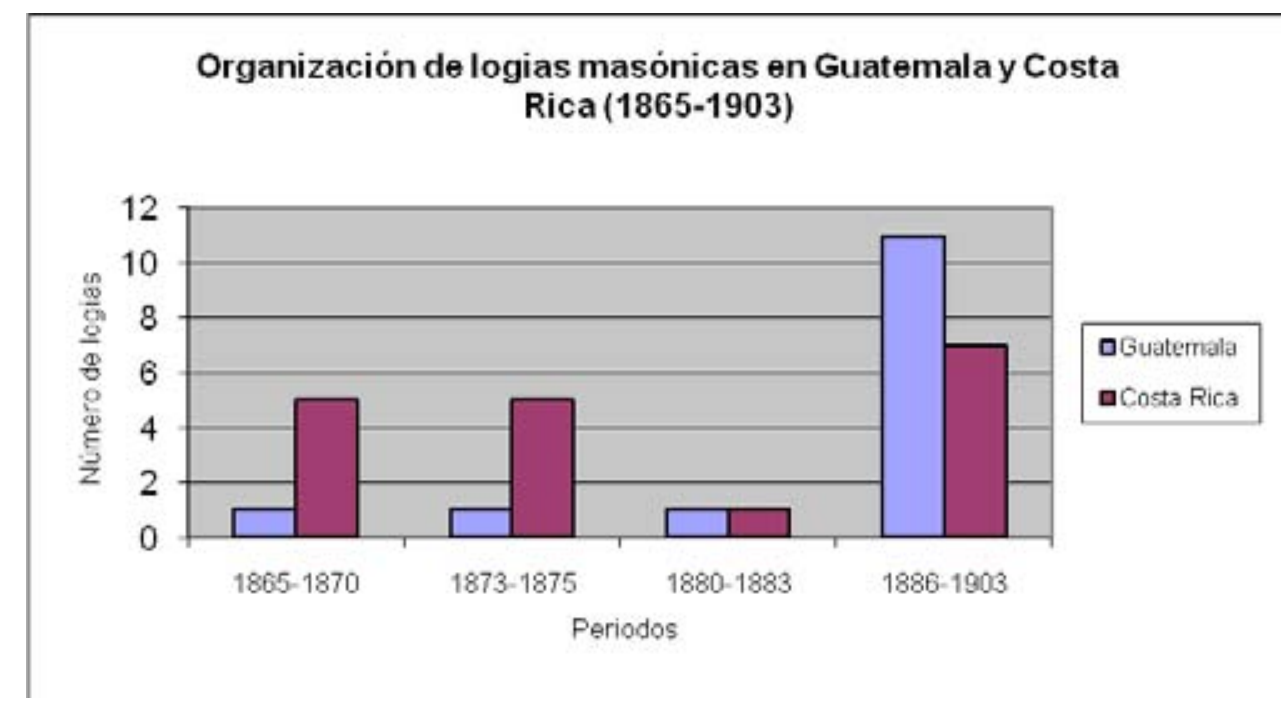

Por otro lado, el Gráfico 1 nos muestra cómo en cada uno de los tres primeros periodos en Guatemala se organizó una sociedad de ideas masónica. Finalmente, durante los años 1886 y 1903, fue tan importante la actividad masónica guatemalteca (se organizaron 11 logias), que en 1888 se traslada la sede del Gran Oriente y Supremo Consejo Centro Americano, de San José a Guatemala ${ }^{17}$ y en 1903 es organizada la Gran Logia de Guatemala. ${ }^{18}$

Hemos observado que el desarrollo de la masonería costarricense y guatemalteca durante los años en estudio experimenta un proceso expansivo bastante complejo y por ende relativamente largo de consolidación. Treinta y cuatro años en Costa Rica y treinta años en Guatemala. ¿Qué factores contextuales condicionaron determinados procesos? ¿Hubo persecuciones religiosas o políticas? Para contestar las preguntas anteriores, hemos decidido explicar el proceso de consolidación de la masonería en ambos países a partir de los periodos identificados de

17 Obregón, Porqué se trasladó a Guatemala el Supremo Consejo Centroamericano, San José, Costa Rica: Imprenta Tormo, 1952

18 Gran Logia de Guatemala, “Antecedentes de la Fundación de la Gran Logia de Guatemala” http://www. granlogiaguatemala.com/historia.htm (Fecha de acceso: 25 de marzo 2008) 
organización de logias: 1865-1870, 1873-1875, 1880-1883 y 1886-1903.

\section{DIFUSIÓN Y EXPANSIÓN BAJO LA GUÍA DEL PRESBÍTERO CALVO}

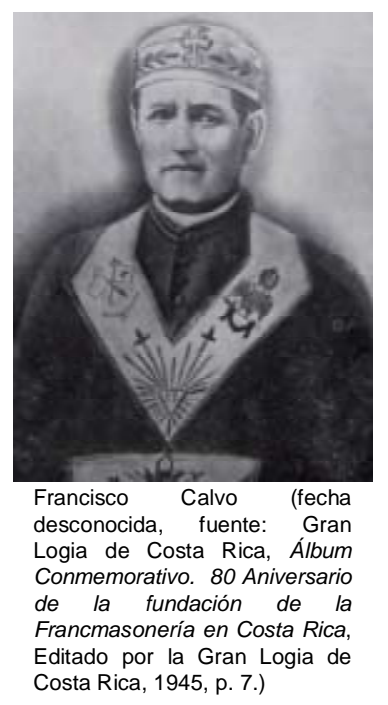

sacerdote católico Francisco Calvo. ${ }^{19}$ Este hecho no hizo esperar la reacción de la Iglesia católica. Campañas de desprestigio de esta forma de sociabilidad por medio de la prensa escrita y por supuesto desde el púlpito fueron la constante. Ante esta situación de impugnación, el presidente José María Castro Madriz (1866-1868) escribe una carta al arzobispo Manuel F. Barrutia, máxima autoridad católica de Guatemala y consejero del obispo costarricense Llorente y le explica que la masonería es una sociedad de beneficencia, que se reúne pacíficamente a discutir asuntos políticos y que no atenta contra la religión; además de que no sería prohibida porque no es una asociación condena por las leyes del país. ${ }^{20}$

A pesar de ello, Llorente, motivado por el sacerdote Domingo Rivas (quien mantendría una lucha personal con Calvo), ${ }^{21}$ publica dos pastorales antimasónicas, la primera el 20 de agosto 19 Calvo había sido iniciado en la logia Cruz Austral del Valle del Callao, Perú, el 20 de junio de 1862. Véase: MGLCR, “Copia auténtica de las Actas de Logia "Cruz Austral”, de Callao, Perú, año de 1862, relativas a iniciación y grados del presbítero Francisco Calvo”, estante 17. Sobre la vida de éste, véase Obregón, Presbítero Doctor Francisco Calvo (Ganganelli). Organizador de la Masonería en Costa Rica, San José: Imprenta Borrase, 1968

20 AGLCR, “Carta del Presidente Castro a Monseñor Barrutia, 10 de abril de 1867”, Espejo Masónico (New York) Publicado por Andrés Cassard

21 Guzmán, "El conflicto Iglesia-Estado-Masonería en Costa Rica bajo el Derecho Canónico: el juicio del Vicario Capitular, Dr. Domingo Rivas, contra el Canónigo Penitenciario, Dr. Francisco Calvo (1873-1876), y la 
y la segunda el 12 de octubre de $1867 .^{22}$ Agregamos que la impugnación de la iglesia local a la masonería fue por su condición de agrupación condenada y prohibida por el Papa, y se caracterizó por reproducir documentos del Magisterio católico. ${ }^{23}$ A pesar de este conflicto, más presbíteros católicos en Costa Rica fueron iniciados masones ${ }^{24}$ y esta sociedad de ideas empezó a crecer rápidamente, como observamos en el reporte de Calvo en setiembre de 1866:

Cada día se aumenta el número de obreros, i obreros cuya adquisición hace honor a nuestras columnas. Se han iniciado en nuestros misterios, de Junio a esta fecha, trece, i han sido adelantados a compañeros dos, después de haber cumplido el tiempo de ley, i las tenidas. Están al proponerse varios que dicen pertenecer a nuestra orden. Parece que cuando la Masonería se vé (sic) más perseguida del fanatismo, es cuando más progreso hace i se aumenta más el número de obreros, como ha sucedido entre nosotros que nada de masones se hablaba, i como se viera atacada, todos procuraban instruirse averiguando su objeto i fin de esta Institución, i viendo que lejos de ser una sociedad inútil i mala, se han convencido de su bondad, así es que sólo la jente (sic) de poca inteligencia i fanática que en un número mui (sic) corto la creen mala i es porque es prohibida como dicen..$^{25}$

Por otro lado, la reacción del cura Calvo fue motivar a los masones a ser tolerantes y prudentes. ${ }^{26}$ Este sacerdote logró fortalecer su imagen en la sociedad costarricense y garantizar el desarrollo de las actividades masónicas; ello explicado por las estrechas relaciones de amistad y parentesco que poseía esta persona con importantes personalidades del país. ${ }^{27}$ Calvo fue el líder de esta sociedad de ideas en Centroamérica hasta el 28 de julio de 1876 cuando decide abjurar de la actividad masónica. ${ }^{28}$ participación vaticana”, Congreso Centroamericano de Historia VII, Tegucigalpa, Honduras, 2004

22 AHACMSJ, Fondos Antiguos (Caja, Tomo, Folios): 48, 1, 141-160. Sobre éstas véase Sanabria, Llorente, 228-231 y Obregón, Masonería, Tomo I, 38-39

23 "El discurso de la Iglesia católica sobre el fenómeno de la masonería en Costa Rica (1865-1899)", 14-15

24 Ibid.

25 AGLCR, Gran Oriente Neogranadino, Rejistro Oficial Masónico (Cartagena) 39 (22 de diciembre de 1866): 367-369

26 Guzmán, "Masonería, Iglesia y Estado: Las relaciones entre el Poder Civil y el Poder Eclesiástico y las formas Asociativas en Costa Rica (1865-1875)", Congreso Centroamericano de Historia VI, Ciudad de Panamá, Panamá, 2002, 8

27 Martínez, "Composición socio-ocupacional de los masones del siglo XIX”, en Diálogos Revista Electrónica de Historia 8, n. 2 (Agosto 2007-Febrero 2008) www.fcs.ucr.ac.cr/ historia/articulos/2007/ vol2/6vol8n2martinez.pdf (Fecha de acceso: 25 de marzo 2008)

28 Abjuración de Calvo en AHACMSJ, Fondos Antiguos (Libro, Tomo, Folio): 99, 1, 328. Y véase 
Bajo la guía de Calvo se desarrollan los dos primeros periodos de la masonería centroamericana. En el periodo de 1865 a 1870 se establecen logias en las ciudades de San José (3) y Puntarenas (2) en Costa Rica, y en la ciudad de Guatemala (1), pero esta última no estuvo motivada por el sacerdote. Por su parte, en los años de 1873 a 1875, en seis ciudades se establecieron seis logias: San José, Alajuela, Cartago, Liberia y Puntarenas en Costa Rica, y en la capital guatemalteca (Cuadros 2 y 3). En total se desarrollaron doce logias, es decir el 37,5\% de las logias de los años en estudio (Cuadro 1).

\section{Gráfico 2}

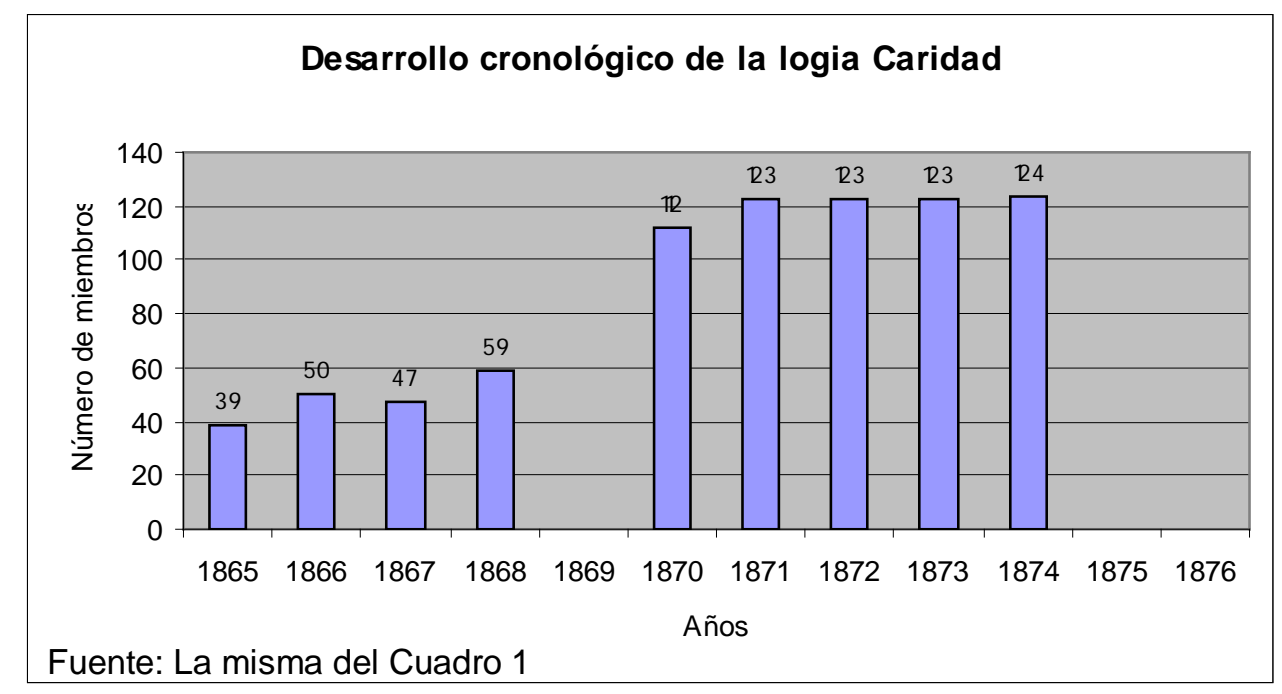

La logia Caridad (la primera en ser organizada), fue sin duda alguna, la sociedad de ideas masónica más importante mientras el sacerdote lideró la masonería centroamericana. En el Gráfico 2 podemos observar el crecimiento y constancia de esta logia. Además esta logia duró 11 años y tuvo el 45\% de los masones durante los periodos bajo la guía del presbítero Calvo.

Cuando analizamos los datos anteriores nos hacemos la siguiente pregunta: ¿por qué se organizan tantas logias si éstas después no se van a poder mantener? La respuesta es sencilla, a mediados de 1870 Calvo considera que es el momento idóneo para que el área posea su propio gran auspiciador. Para dicha organización se necesita la existencia de más logias, por lo que Calvo solicita cartas constitutivas al Gran Oriente y Supremo Consejo Neo-Granadino y se establecen

Obregón, Presbítero Doctor Francisco Calvo, 82-86 
tres logias más ${ }^{29}$ (Cuadro 1). Ya en enero de 1871 existen en Costa Rica cinco logias, por lo que el 9 de enero del mismo año se organiza en San José el Gran Oriente y Supremo Consejo Centro Americano, institución que además quedaría bajo el liderazgo de este sacerdote. ${ }^{30}$ A partir de ese momento, se lucharía por la difusión de la masonería no sólo por todo el país (Mapa 1 y Cuadro 2), sino también por el resto de Centroamérica. ${ }^{31}$

Por otra parte, habíamos señalado que el Gran Oriente de Colón organizó en 1870 una logia en la ciudad de Guatemala, logia que de paso tuvo actividad por tan sólo unos meses. Entonces nos preguntamos: ¿cómo este gran auspiciador organiza masonería en este país cuando en teoría la jurisdicción la posee el Gran Oriente y Supremo Consejo Neo-Granadino? Para responder a lo anterior, encontramos dos posibles explicaciones, en primer lugar no sabemos si los organizadores de esta logia tenían conocimiento del proyecto masónico impulsado por Calvo o relaciones antiguas con la masonería cubana. Por otro lado, durante esta coyuntura es normal encontrar conflictos entre grandes auspiciadores por la jurisdicción de determinados territorios, donde Centroamérica no fue la excepción. ${ }^{32}$

Luego, en 1873 se organiza la logia Hiram en la capital guatemalteca por parte del español José Quirce, miembro de Caridad. ${ }^{33}$ Ésta fue la primera sociedad de ideas masónica en Guatemala auspiciada por Calvo. ${ }^{34}$ Consideramos que el entorno guatemalteco ofreció las condiciones necesarias para el establecimiento de una sociedad de ideas masónica, gracias a los cambios estructurales sufridos desde 1871, que propiciaron el desarrollo de este tipo de

29 Obregón, Masonería, Tomo I, 41-45

30 Ibid., Tomo II, 4-16; y Guzmán, "La fundación del Supremo Consejo Centroamericano y la revolución de 1870 en la construcción de un Estado Liberal democrático en Costa Rica”, I Simposio Internacional de Historia de la Masonería Latinoamericana y Caribeña, La Habana, Cuba, 2007

31 Obregón, Masonería, Tomo II, 17-25 y 67-88; Francisco Medal, La historia de la Francmasonería en Nicaragua, Managua: Gran Logia de Nicaragua, 1927; José Oller, Historia del Supremo Consejo Nacional de Panamá, Panamá: Ediciones de la Imprenta Hernández, 1934; Federico Góngora Herrera, Documentos de la Masonería Centroamericana (Antigua y Aceptada). Desde el año 1824-1933, Serenísima Gran Logia de Costa Rica, San José: Imprenta Española, 1937 y Mis últimos documentos de la Masonería Centroamericana Antigua y Aceptada. Años 1809-1939, Serenísima Gran Logia de Costa Rica, San José, 1940 y Francisco J. Ponte Domínguez, Historia de la Masonería Salvadoreña, Sonsonate: Imprenta Excélsior, 1962

32 Guzmán, "Andrés Cassard y las masonerías cubana y colombiana en la fundación de la masonería centroamericana: relación de un protagonismo personal en tres jurisdicciones (1865-1877)”, I Simposio Internacional de Historia de la Masonería Latinoamericana y Caribeña 33 Obregón, Masonería, Tomo II, 67-88

34 AGLCR, Boletín Oficial del Gran Oriente y Supremo Consejo Centro Americano 9, 17. Además véase Obregón, José Quirce Filguera, fundador de la masonería en la República de Guatemala 
sociabilidad. Hablamos de reformas liberales,$^{35}$ por lo que no podemos olvidar que durante el siglo XIX en Centroamérica el desenvolvimiento de la masonería va a ser completamente paralelo al del liberalismo. ${ }^{36}$

Por otro lado, si retomamos el Gráfico 1, observamos que entre 1865 y 1876 existe un desenvolvimiento estable en la organización de sociedades de ideas masónicas. De organizar cinco logias en el primer periodo, se organizan seis en el segundo. Si bien la Iglesia católica continuaba con su propaganda antimasónica y recordando que pertenecer a la masonería es pecado, ${ }^{37}$ fue más el poder político que el religioso el que trajo problemas a la actividad masónica. ${ }^{38}$

Por otra parte, es indudable la influencia eclesial en los sectores medios-bajos de la sociedad centroamericana de la época, ${ }^{39}$ por lo que para estos periodos, la masonería va estar ante todo constituida por miembros de sectores medios-altos en su mayoría. (Además recordemos que para ingresar a la masonería se debe saber leer y escribir, lo cual ya dice bastante del nivel socioeconómico del masón decimonónico en Centroamérica). ${ }^{40}$ El hecho de que en estos 35 José Cal, "La Iglesia de Guatemala ante la Reforma Liberal (1871-1878)", Estudios (agosto 2000): 148191; Julio Castellanos Cambranes, Aspectos del desarrollo económico y social de Guatemala, a la luz de fuentes históricas alemanas (1868-1885), Guatemala: FLACSO, 2007, 81-149; Arturo Taracena Arriola, "Liberalismo y Poder en Centroamérica (1870-1929)", en Víctor Hugo Acuña Ortega, Historia General de Centroamérica. Las Repúblicas Agroexportadoras, Tomo IV, Madrid: FLACSO, 1993, 179-185

36 Arturo Piedra Solano, Arturo, "Notas sobre la relación entre liberalismo, francmasonería y penetración protestantes en Centroamérica”, Bastian, Protestantes, liberales y francmasones. Sociedades de ideas y modernidad en América Latina, siglo XIX, 119-131. Para el caso específico de Costa Rica: Guzmán, "El paisaje de la Nación: Liberalismo, masonería y redes sociales en la reorganización del uso del poder en el Estado. Costa Rica 1870-1882”, Congreso Internacional de la Asociación de Historiadores Latinoamericanos Europeos XIV, Castellón, España, 2005 y "Liberalismo, Educación, Iglesia y Masonería: el proceso de formación y secularización del Estado Nacional a través de las relaciones institucionales en Costa Rica en el siglo XIX”, Tesis Doctoral, Universidad de Zaragoza, Zaragoza, 2005

37 Martínez, "Representaciones sociales sobre la Masonería en Costa Rica (1865-1899)", I Simposio Internacional de Historia de la Masonería Latinoamericana y Caribeña

38 Guzmán, "Masonería, Iglesia y Estado: La tolerancia y los mecanismos de represión asociativa y religiosa en Costa Rica (1865-1880)", Congreso Centroamericano de Historia III, San José, Costa Rica, 1996; Ibid., "Masonería, Iglesia y Estado: Las relaciones entre el Poder Civil y el Poder Eclesiástico y las formas Asociativas en Costa Rica (1865-1875)"; y Martínez, "Consolidación de la Masonería en Costa Rica (18651899)", Jornadas de Investigación Histórica, CIHAC, Universidad de Costa Rica, San José, Costa Rica, 2006 39 Para el caso costarricense véase José Daniel Gil Zúñiga, El culto a la Virgen de los Ángeles (1824-1935). Una aproximación a la mentalidad religiosa en Costa Rica, Alajuela: MHJS, 2004, 9-40. Y para el guatemalteco: Manuela Canton Delgado, Bautizados en fuego. Protestantes, discursos de conversión y política en Guatemala (1989-1993), Madrid: Ed. CIRMA/PMS, 1998, 74-82; y Ricardo Bendaña Perdomo, La Iglesia en Guatemala. Síntesis histórica del catolicismo, I Parte 1524-1821, Artemis-Edinter, Guatemala, 1996

40 Martínez, "Composición socio-ocupacional de los masones del siglo XIX" 
dos periodos, la presión de la Iglesia católica no llevara al cierre de la actividad masónica, se explica en que tres de los cuatro presidentes de Costa Rica entre 1865 y 1876, ${ }^{41}$ y el presidente Justo Rufino Barrios y Auyón (1873-1885) en Guatemala para 1873, eran miembros de logias masónicas. Incluso el presidente costarricense Castro Madriz se había declarado "Gran Protector de la Masonería". ${ }^{42}$

Entre 1868 y 1869 se desarrolla una crisis en las actividades masónicas durante el gobierno de Jesús Jiménez (1868-1870), quien según Obregón ${ }^{43}$ concebía a los masones como un grupo de conspiradores y enemigos del gobierno. En palabras de Cleto González Víquez, Jiménez veía las reuniones de masones como "...tenidas (que) eran foco de opositores y antro de proyectos subversivos...”;4 por lo que este presidente prohibió con las fuerzas armadas las reuniones en logia. ${ }^{45}$ Agregamos además, que sin duda, este gobierno estuvo aliado a las políticas dictadas por el obispo Llorente. ${ }^{46}$ Finalmente el hecho de que Jiménez eliminara la libertad de prensa, también vendría a afectar la actividad masónica, ello porque muchos masones estaban asociados al desarrollo de ésta. ${ }^{47}$

Durante los años 1873 a 1876, las actividades masónicas van a experimentar un declive. Habíamos indicado que quienes ostentaban el poder eran masones y decimos que la Iglesia católica no fue factor fundamental para que la masonería guatemalteca y costarricense entrara en crisis, entonces ¿qué sucedió? La respuesta la fundamentamos en dos razones: una propia de la orden y otra política. En primer lugar, el líder de la masonería parece que se interesó más por la difusión y expansión de esta sociabilidad que por el cuidado de la orden, lo cual está claro en los datos presentados. Además debemos señalar que las jerarquías masónicas se encontraban

$41 \quad$ Ibid.

42 Guzmán, “Dr. José María Castro Madriz: Masón y liberal, diputado, embajador, ministro, Presidente de la República, Presidente del Congreso, Presidente de la Corte Suprema de Justicia”, en Ferrer, La masonería española en la época de Sagasta (1825-1903), CEHME y la Fundación Práxedes Mateo-Sagasta, Universidad de Zaragoza, Universidad de La Rioja, Logroño, 2006, 957

43 Obregón, Masonería, Tomo I, 38-40

44 Cleto González Víquez, Obras históricas, San José: EUCR, 1973, 288-298

45 Obregón, Hechos militares y politicos, Alajuela: Imprenta Nacional, 1981, 152-158 y "La segunda caída del Dr. Castro", mimeografiado, San José, Costa Rica, 1968; Montúfar, 244-251; y Yamileth González García, "La segunda administración del Dr. José María Castro Madriz (1866-1868)", Tesis de Licenciatura en Historia, Universidad de Costa Rica, 1971, 128-139 y 197-223

46 Claudio Vargas Arias, El Liberalismo, la Iglesia y el Estado en Costa Rica, Editorial Guayacán, 1990,

62

47 Montúfar, 239-244; Patricia Vega Jiménez, "El mundo impreso se consolida. Análisis de los periódicos costarricenses (1851-1870)", Revista de Ciencias Sociales 70 (diciembre 1995): 83-96 
divididas.

En 1875 para las elecciones de Gran Maestro del Gran Oriente y Supremo Consejo Centroamericano había dos candidatos principales: Andrés Sáenz y Manuel Bonilla. Ninguno obtuvo los votos necesarios para ganar las elecciones, entonces buscando el consenso se optó por mantener en el cargo a Francisco Calvo. Esta determinación no fue del agrado de los diferentes líderes masones, por lo que hubo una división. División que un año después se concretaría con el cierre de actividades de todas las logias. ${ }^{48}$

En segundo lugar, encontramos una razón política. Entre 1873 y 1876, Centroamérica vive una época de crisis, emigrantes del área planean revoluciones desde Costa Rica; el país experimenta cinco intentos de insurrección; y se dan problemas limítrofes con Colombia y Nicaragua, hasta el punto de que se habla de guerra. ${ }^{49}$ Esto ocasionó que muchos masones en el país se concentraran en ello más que en preservar una sociedad de ideas como la masonería. ${ }^{50}$ También esta crisis provocó que muchos masones extranjeros volvieran a sus países. ${ }^{51}$ (Vale señalar la importancia de la presencia extranjera en las logias de Costa Rica, la cual rondó alrededor del $41 \%$ del total de miembros de las distintas logias). ${ }^{52}$

Además, recordemos que desde la muerte del obispo Llorente, el liderazgo de la Iglesia católica en Costa Rica quedó en manos del presbítero Rivas. ${ }^{53}$ Éste poseía como político de su confianza a Vicente Herrera, quien luego de los intentos de insurrección contra Guardia, se convertiría en la mano derecha del presidente. ${ }^{54}$ Según Guzmán, Guardia vio en una alianza con la Iglesia católica, la posibilidad de mantenerse por mucho tiempo en el poder. ${ }^{55}$ Finalmente el 28 de julio de 1876, sucedió un acontecimiento que marcó la masonería en el área por muchos años, la renuncia de su organizador y guía durante once años.

\footnotetext{
48 Obregón, Masonería, Tomo II, 31-32

$49 \quad$ Ibid., Hechos militares y politicos, 170-178

50 Muchos de los masones de este periodo eran miembros de las redes políticas del país. Véase Martínez, "Composición socio-ocupacional de los masones del siglo XIX"

51 Montúfar, 315-322

52 Martínez, "Composición socio-ocupacional de los masones del siglo XIX"

53 Sanabria, La primera vacante de la Diócesis de San José 1871-1880, San José: ECR, 1973; y Vargas, 69-76

54 Guzmán, "Masonería, Iglesia y Estado: Las relaciones entre el Poder Civil y el Poder Eclesiástico y las formas Asociativas en Costa Rica (1865-1875)"

55 Ibid.
} 


\section{PERSECUCIÓN, CRISIS Y DIVISIÓN}

El panorama político de Costa Rica llevaría a la masonería a una crisis que se agravaría con la renuncia de Calvo. En 1876 es suspendida la Constitución política, condición que permanecería hasta 1882. En las elecciones del 2 de abril de 1876, el candidato único, el masón Aniceto Esquivel ganaría las elecciones, pero sería derrocado el 30 de julio del mismo año por no apoyar un enfrentamiento bélico con Nicaragua. ${ }^{56}$ Vicente Herrera lo sustituyó, pero en 1877 Guardia tomaría el poder absoluto del país. ${ }^{57}$ No habrá más actividad masónica en Costa Rica hasta después de la muerte del dictador. ${ }^{58}$

El suspender las garantías de la Constitución no sólo provocó que muchos extranjeros líderes masones regresaran a sus países, sino que también muchos costarricenses opositores políticos de Guardia fueran exiliados, ${ }^{59}$ de los cuales, muchos pertenecían a la masonería. Incluso en El Salvador en 1879, se constituiría una Liga Antiguardista bajo el liderazgo de masones exiliados. ${ }^{60}$ También otros -entre estos masones- por la situación del país, simplemente deciden emigrar.

A esto cabe agregar que el nuevo vicario, Luis Bruschetti, desde su nombramiento en 1877 se valió de los artículos del Concordato para continuar la lucha contra la masonería. ${ }^{61}$ A pesar de lo anterior, algunos costarricenses siguieron ligados a la actividad masónica, pero ahora en el resto de Centroamérica. Incluso, el costarricense Manuel Antonio Bonilla Carrillo se convertiría en el sustituto de Calvo como líder de esta asociación a nivel centroamericano. ${ }^{62}$

Por su parte, en Guatemala, la logia Hiram también cerraría actividades, ello a pesar del ambiente político favorable a este tipo de sociedad de ideas. Sin embargo, como hemos dicho,

\footnotetext{
56 Obregón, Hechos militares y políticos, 179-181

57 Orlando Salazar Mora, El Apogeo de la República Liberal en Costa Rica 1870-1914, San José: EUCR, 1998, 177-178

58 Guzmán, "Masonería, civilismo y autoritarismo. Las logias y el uso del poder en Costa Rica 1870-

1877”, en Ferrer, La masonería española en la época de Sagasta (1825-1903) y “El paisaje de la Nación:

Liberalismo, masonería y redes sociales en la reorganización del uso del poder en el Estado. Costa Rica 1870$1882 "$

59 Obregón, Hechos militares y políticos, 195-198

60 Martínez, "Consolidación de la Masonería en Costa Rica (1865-1899)"

61 Sanabria, La primera vacante de la Diócesis de San José 1871-1880, 167-188; Vargas, 74-77; y

Guzmán, "La "Cuestión Confirma" y la represión ideológica: El debate entre el clero reaccionario, el clero liberal y masón y la autoridad vaticana en Costa Rica (1870-1880)"

62 Obregón, Masonería, Tomo II, 33
} 
las transformaciones estructurales en la sociedad guatemalteca continuaron y ya para 1880 se está organizando un nueva logia en la capital con el nombre de Concordia. Logia organizada por Lorenzo Montúfar y el médico estadounidense Charles Wellington Fitch, pero auspiciada por el Supremo Consejo del Sur de los Estados Unidos, ${ }^{63}$ por razones que aún desconocemos no mantendría sus actividades por mucho tiempo.

El hecho de que un gran auspiciador extranjero organizara una logia en Guatemala en este momento, lo comprendemos por dos razones, por un lado debemos recordar la crisis que estaba experimentando la masonería centroamericana y por otro lado, que el nuevo modelo económico en el país había propiciado una fuerte emigración. ${ }^{64}$ Emigrantes que demandaron el establecimiento de espacios de sociabilidad a los cuales estaban acostumbrados, entre ellos la logia masónica. ${ }^{65}$

Por otro lado, la nueva dinámica que adquirió la sociedad costarricense con la organización de logias masónicas, hizo que la Iglesia católica activara sus tribunales de justicia e iniciara un seguimiento a lo que ésta considerara como irregular, delictivo o simplemente pecado. Términos que parecieran para este momento sinónimos. ${ }^{66}$ Entre 1874 y 1881 encontramos 21 casos de ajusticiamiento eclesial debido a la masonería. ${ }^{67}$

Años después, en 1882 precisamente antes de morir, Guardia restablece la Constitución política en Costa Rica. Con su muerte llega al poder el masón Próspero Fernández (18821885), quien establece una serie decretos que pretenden secularizar la sociedad costarricense, ${ }^{68}$ inclusive el 28 de julio de 1884 deroga el Concordato. ${ }^{69}$ Son restablecidos los derechos y

$63 \quad$ Ibid., 73-74

64 Ciro Cardoso y Héctor Pérez, Centro América y la Economía occidental (1520-1930), San José: EUCR, 1977, 240-242; Castellanos, 133-149; Piedra, 82-88

65 Ricardo Bendaña, "Guatemala”, en Dussel, Historia General de la Iglesia en América Latina, 298; y Mario Samper, "Café, trabajo y sociedad en Centroamérica (1870-1930): Una historia común y divergente", en Acuña, 35-39

$66 \quad$ No debemos olvidar las continuidades de muchas estructuras eclesiales coloniales, prácticamente en toda la Latinoamérica post independiente. Sobre esto véase François-Xavier Guerra, "De la política antigua a la política moderna: invenciones, permanencias, hibridaciones" y Julio Pinto Vallejos, "De proyectos y desarraigos: la sociedad latinoamericana frente a la experiencia de la modernidad (1780-1914)", Ponencias 19th. Internacional Congreso of Historical Sciences, University of Oslo, 6-13 August, 2000

67 AHACMSJ, Fondos Antiguos (Caja, Tomo, Folios): 226, 2, 2-20, 21-37, 68-69; 240,185; 254, 295; 416, 342

68 Ricardo Blanco Segura, 1884. El Estado, la Iglesia y las Reformas liberales, San José: ECR, 1984; Vargas, 135-149; y Sanabria, Bernardo Augusto Thiel, San José: ECR, 1982, 109-150

$69 \quad$ Vargas, $145-148$ 
garantías fundamentales, libertad de prensa, asociación, pensamiento y expresión. ${ }^{70}$ Luego de Fernández llegaría a la presidencia el también masón Bernardo Soto (1885-1889), quien además recibiría el título de "Gran Protector de la Orden Masónica". ${ }^{71}$ Con este nuevo panorama se buscó restablecer la actividad masónica en este país.

El 9 de marzo de 1883 un grupo de masones de las antiguas logias costarricenses se reunieron con el objetivo de organizar una nueva logia, la cual tuvo el nombre simbólico de Unión. Luego para aprovechar los instrumentos de la antigua logia Unión Fraternal, se le agregó al nombre la palabra fraternal. A esta logia se le asignó el número 19. La logia inició actividades con un muy buen panorama, reunió a 61 masones antiguos e inició a 20 personas en su primer año. ${ }^{72}$ Pero esto sólo fue el inicio, ya que por el resto de su existencia la división en la orden continuó hasta el cese de actividades de la logia. Esta división según Obregón fue el resultado de la falta de un liderazgo fuerte que creara diálogo y unidad en la logia. ${ }^{73}$

La última reunión de Unión Fraternal 19 se registra en enero de 1887. Esta logia duró cuatro años, tuvo el $13 \%$ de los miembros de logias costarricenses de los años en estudio, pero apenas inició el 6\%. ${ }^{74}$ Esta logia cerró actividades sin lograr entre los masones de Costa Rica el significado de su nombre. Esta inconsistencia en la masonería costarricense desde 1876 obligó que se trasladara el Gran Oriente y Supremo Consejo Centro Americano a la ciudad de Guatemala, perdiendo Costa Rica el protagonismo en el área. La solicitud del traslado fue hecha por los masones Wilhelm Nanne y Felix Matos, importantes líderes de la masonería guatemalteca. ${ }^{75}$ Nanne había formado parte de las dos logias Unión Fraternal en Costa Rica, pero se trasladó a Guatemala debido a su trabajo en el ferrocarril; éste fue uno de los principales promotores de la masonería en Centroamérica luego de la abjuración de Calvo.

\footnotetext{
70 Guzmán, “Dr. José María Castro Madriz”, 945

71 AGLCR, "Libros de Actas Unión Fraternal 19, 9 marzo 1883-5 marzo 1886"

72 Ibid., "Registro de firmas Respetable Logia Unión No 19, 1883-1886"

73 Obregón señala que los libros de actas de los últimos años de reunión de esta logia se perdieron, así que es difícil determinar las causas que originaron un cisma en el seno de la logia; Obregón, Masonería, Tomo II, 4849

74 Martínez, "Consolidación de la Masonería en Costa Rica (1865-1899)"

75 Obregón, Masonería, Tomo II, 49-53
} 


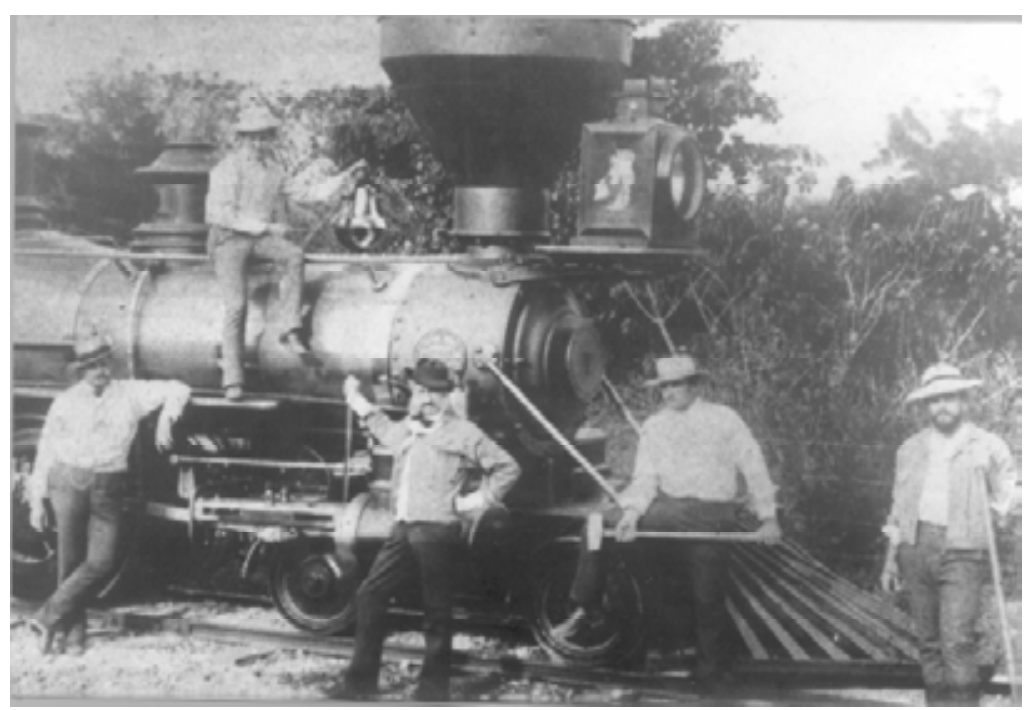

Máquina No 1 de Ferrocarriles de Guatemala, S. A. De derecha a izquierda la familia Nanne: Federico, Roberto, Guillermo (el padre), Ricardo y Alfredo. Guillermo fue iniciado en la logia Unión Fraternal 7 en 1871, llegando a ser Venerable Maestro de dicha logia en 1875 y Gran Comendador del Supremo Consejo Centroamericano entre 1887 y 1895; por su parte Ricardo fue iniciado en la logia Unión Fraternal 19 en 1884 y entre 1893-1900 fue Venerable Maestro de la logia Regeneración.

Fuente: Archivo privado de Ricardo Muñoz Nanne y Martínez, "Base de datos Masonería en Costa Rica (1865-1899)".

Por otra parte, en este periodo contrario al anterior, el panorama político-religioso costarricense fue totalmente favorable para el desarrollo de sociedades de ideas masónicas, pero a pesar de ello, la masonería experimentó un tiempo de crisis y división.

\section{UNIDAD Y DIÁLOGO: FORTALECIMIENTO DE LA MASONERÍA EN COSTA RICA Y GUATEMALA}

En 1887 fue trasladado el Gran Oriente y Supremo Consejo Centro Americano de la capital costarricense a la guatemalteca, no sólo por la crisis que experimentaba la masonería en Costa Rica, sino también por el auge que vivía esta sociedad de ideas en Guatemala. En 1886 fue organizada en Ciudad de Guatemala, la logia Unión, ${ }^{76}$ ello luego de varios años sin actividad masónica; al año siguiente en la misma ciudad se organiza la logia Libertad y la logia Fraternidad en Antigua, capital de Sacatepéquez. ${ }^{77}$ Vemos entonces que para 1887 Costa Rica se queda sin actividades masónicas, mientras que Guatemala posee en funcionamiento a tres logias, lo cual explica el traslado del gran auspiciador centroamericano.

Para 1888 es organizada la logia Fénix en Quezaltenango ${ }^{78}$ la cual hoy día aún funciona.

76 Vale señalar que esta logia ha estado en actividades ininterrumpidas hasta hoy día.

77 Obregón, Masonería, Tomo III, 43

78 Ibid., 114 
Notamos hasta ahora una primera expansión espacial de la masonería en Guatemala, ¿por qué? Bueno, nos encontramos en una etapa de la historia guatemalteca, donde el gobierno liberal de Manuel Lisandro Barillas (1885-1892) ${ }^{79}$ garantiza el desenvolvimiento de este tipo de sociedades de ideas. Por otra parte, las ciudades donde se establecen las logias son las más importantes del país, la capital guatemalteca; Sacatepéquez y Quezaltenango, ciudades con importante crecimiento económico, modernización y altos índices de emigración debido al desarrollo del café. $^{80}$

Mientras tanto, en noviembre de 1888, nuevamente un grupo de antiguos masones se reunió para retomar la actividad masónica en Costa Rica, con lo cual inicia este país el último periodo. Los masones en Costa Rica esta vez logran terminar "con viejas diferencias" unidad reinician el trabajo masónico en el país. El éxito de esta reunión lo vemos además reflejado en el hecho de que hasta hoy día, la masonería ha realizado labores de manera ininterrumpida; siendo el mismo caso en Guatemala con la organización la logia Unión.

El cuarto periodo inicia con la organización de las logias Unión y Regeneración, en Guatemala y Costa Rica respectivamente, es sin duda alguna el momento más positivo para la masonería en ambos países. Podemos determinar a partir del Gráfico 1 que en este periodo, la línea de crecimiento tiende a ser positiva. Además si retomamos el Cuadro 1, vemos que el $58 \%$ de las logias centroamericanas existentes entre 1865 y 1903, estuvieron organizadas en Guatemala (35,5\%) y en Costa Rica (22,5\%), y pertenecieron a este último periodo.

Desde la fundación de las sociedades de ideas Unión y Regeneración, funcionaron diez y seis logias más en Guatemala y Costa Rica respectivamente. En el primer país en siete ciudades distintas (Guatemala, Sacatepéquez, Quetzaltenango, Retalhuleu, Totonicapán, San Marcos y Alta Verapaz) y en el segundo en dos (San José y Limón). ${ }^{82}$

El desarrollo expansivo de las actividades masónicas en Guatemala, lo explicamos en que estas ciudades, recibieron estructuralmente bien las transformaciones de los gobiernos liberales, lo cual las condicionaba socialmente para organizar este tipo sociabilidades. Agregamos además, la alta migración de europeos y estadounidenses protestantes promovida por los gobiernos

$79 \quad$ Piedra, 122-123 y Taracena, 184-185

80 Sobre esto véase Regina Wagner, Historia del Café en Guatemala, Guatemala: Villegas Editores, 2003, 103-116 y Samper, 17-25

81 Obregón sostiene que en la reunión para organizar la logia Regeneración se solucionaron problemas que habían ocasionado división, esto sin hondar en ellos; Obregón, Masonería, Tomo III, 4-6

82 Cuadro 1, Cuadro 2 y Mapa 1 
guatemaltecos ${ }^{83}$ que no sólo ayudó a los cambios dirigidos por el Estado que buscaba una religión pragmática y adecuada al modelo económico impuesto, sino que colaboró en la expansión de actividades masónicas. ${ }^{84}$ Sumamos también, el hecho de que en mayo de 1892, el presidente de la República José María Reyna Barrios (1892-1898), sobrino de Justo Rufino Barrios, se declara "Gran Protector de la Masonería en Guatemala". ${ }^{5}$

Por otra parte, el hecho de que la masonería costarricense se concentrara en sólo dos ciudades, está en la importancia de San José como capital; y por el desarrollo socioeconómico en la ciudad de Limón a raíz de la industria bananera y la construcción del ferrocarril. ${ }^{86}$ A Limón llegaron muchos extranjeros masones o con tradición familiar masónica, por lo que unirse a las logias costarricenses e incluso sobresalir en ellas no era de extrañarse. También algunos de los trabajadores afrocaribeños que llegaron a la costa atlántica desarrollaron dos logias clandestinas que duraron apenas unos meses. ${ }^{87}$

Agregamos que en este periodo, el más exitoso de la masonería costarricense en el siglo XIX, el panorama político-religioso en teoría debió ser completamente adverso, ya que se desarrollaron los regímenes autoritarios de José Joaquín Rodríguez (1890-1894) y Rafael Iglesias (1894-1902) ${ }^{88}$ Y recordemos que en momentos con tónicas similares como los segundos gobiernos de Jiménez (1868-1870) y de Guardia (1876-1882), la actividad masónica experimentó tiempos de crisis. Por otra parte, durante este periodo encontramos la mayor impugnación y lucha de la Iglesia católica hacia la sociabilidad masónica, fueron publicados 64 artículos antimasónicos y un manual antimasónico, ${ }^{89}$ incluso hubo un partido político católico que buscó

83 Estos incluso empezaron a instalar misiones en el país. Véase Heinrich Schäfer, Protestantismo y crisis social en América Central, San José: EEI, 1992, 242-243

$84 \quad$ Piedra, 119-131; y Bastian, "La implantación y el desarrollo del efecto de doctrina y efecto de organización en el protestantismo misional en América Latina”, en Hans Jürgen, Religiosidad e Historiografía.

La irrupción del pluralismo religioso en América Latina y su elaboración metódica en la historiografia, Alemania: Vervuert-Iberoamericana, 2004, 61-70

85 Obregón, Masonería, Tomo III, 44

86 Jeffrey Casey, Aspectos económicos de la industria bananera: 1883-1940, San José: ECR, 1979, cap. 3

87 Guzmán, "Las Logias de Mecánicos de Limón (C.R.): Destrucción y Reconstrucción del Espíritu Asociativo de la Población Negra Caribeña”, Congreso Centroamericano de Historia II, Universidad de San Carlos, Ciudad de Guatemala, Guatemala, 1993

88 Explica Claudio Vargas que estos gobiernos fueron favorables a los intereses de la Iglesia. Véase: Vargas, 189-194

89 Hemeroteca de la Biblioteca Nacional, Periódico Unión Católica, 1890-1896 y AHACMSJ, Eco Católico 1890, 1893 y El Adalid Católico 1895-1896. Un análisis en Martínez, "El discurso de la Iglesia católica sobre el fenómeno de la masonería en Costa Rica (1865-1899)" 
entre otras cosas combatir la masonería..$^{90}$

Sin embargo, entre 1888 y 1899 lo que sucedió es que la masonería costarricense se despolitizó, lo cual hizo que no afectara el ambiente político y religioso hostil en la logia; por su parte, en Guatemala más bien la masonería se politizó. En Costa Rica, la mayoría de masones políticos los encontramos en los años anteriores. De los presidentes, ministros y diputados asociados a la masonería, sólo un $10 \%$ perteneció a estos años. En este periodo, vamos a encontrar una mayoría de miembros extranjeros y cuyas ocupaciones son la empresa y el comercio. ${ }^{91}$ Por otra parte, debemos recordar que desde la década anterior (1880's) habían sido establecidas las bases jurídicas (en donde sobresale el Código civil de 1888, ${ }^{92}$ que garantizaban los derechos necesarios (libertades de expresión y asociación) para terminar de consolidar una sociabilidad como la masonería.

El desarrollo de las actividades masónicas en Guatemala y Costa Rica a partir de 1886 fue tan importante, que se lograron las bases necesarias para organizar grandes auspiciadores en cada país en 1903 y 1899 respectivamente. La fundación de dichas instituciones significaría que jurídicamente estos países ya no dependerías de grandes auspiciadores extranjeros, se hablaría ahora de una masonería nacional.

\section{Conclusiones}

Entre 1865 y 1903 se consolida la masonería en Costa Rica y en Guatemala. En el primer país en 1899 con la organización de la Gran Logia de Costa Rica y en el segundo en 1903 con la organización de la Gran Logia de Guatemala. En enero de 1865 se organizó formalmente la primera logia centroamericana en San José, Costa Rica. Este proceso de consolidación lo hemos divido en los cuatro periodos de organización de logias identificados: de 1865 a 1870, de 1873 a 1875, 1880 a 1883 y de 1888 a 1899.

El periodo 1865-1870 es de crecimiento y difusión de logias masónicas, ello con el objetivo de organizar un gran auspiciador para Centroamérica. En los años 1873-1875 se seguiría la

90 Clara Di Luca Laurito, "Partido Unión Católica, primer partido ideológico de Costa Rica", Tesis de Licenciatura, Escuela de Historia, Universidad de Costa Rica, 1973; Carlos Enrique Carranza Villalobos, "Partido Unión Católica y su importancia en la vida política de Costa Rica”, Tesis de Licenciatura, Escuela de Ciencias Políticas, Universidad de Costa Rica, 1982

91 Martínez, "Composición socio-ocupacional de los masones del siglo XIX"

92 Salazar, 247-249 
misma tónica. En estos periodos fueron fundadas un total de 12 logias en 6 ciudades diferentes entre ambos países. La mayoría de estas logias fracasaron. Estos periodos se caracterizaron por estar guiados por el presbítero Calvo, quien había protegido a esta sociedad de ideas de la persecución eclesial no sólo por su status de clérigo sino por sus relaciones familiares y de amistad con los distintos gobernantes.

Entre 1876 y 1882, el gobierno costarricense de Guardia experimentó un periodo inconstitucional, por lo que la actividad masónica centroamericana inicia una época de altibajos. Esta época termina en 1886 en Guatemala con la fundación de la logia Unión y en 1888 en Costa Rica cuando un grupo de masones deciden fundar la logia Regeneración. Estas logias crecieron a tal grado que se convertieron en la base de la organización de la Gran Logia de Guatemala en 1903 y la Gran Logia de Costa Rica en 1899. 